\title{
A ATUAÇÃo dA ADVOCACIA PÚBLICA NA SOLUÇÃo CONSENSUAL DOS CONFLITOS ENVOLVENDO A ADMINISTRAÇÃO PÚBLICA NO BRASIL
}

Sílzia Alves Carvalho. Professora permanente do Programa de Mestrado Profissional em Direito e Políticas Públicas da Universidade Federal de Goiás. Doutora em Direito pela Pontifícia Universidade Católica de São Paulo (2006). Mestre em Direito pela Pontifícia Universidade Católica de São Paulo (2001). Graduada em Direito pela Pontifícia Universidade Católica de Goiás (1991). Endereço postal: Praça Universitária. Setor Leste Universitário, Goiânia-GO,CEP 74.605-220.E-mail: silzia.ac@gmail.com.

Rafael Carvalho da Rocha Lima. Mestrando do Programa de Mestrado Profissional em Direito e Politicas Públicas pela Universidade Federal de Goiás. Pós-graduado em Direito Civil e Direito Processual Civil pela Universidade Cândido Mendes (2008). Graduado em Direito pela Universidade Federal de Goiás (2004). Endereço postal: Av. Deputado Jamel Cecílio, $n^{o}$ 3455, Jardim Goiás, Ed. Flamboyant Park Business, sala 1109, Goiânia - GO, CEP 74.810-100. E-mail: rafaelcrlima@gmail.com

\section{Resumo:}

O acentuado grau de litigiosidade na sociedade brasileira tem produzido elevadas taxas de congestionamento no Judiciário. A Fazenda Pública constitui uma das maiores litigantes do país. As demandas envolvendo a administração pública não devem ser necessariamente equacionadas pelo Estado-Juiz. Esse trabalho busca discutir os impactos das mudanças ocorridas no ordenamento jurídico brasileiro a partir de 2015 no tocante a utilização dos métodos consensuais de solução de conflitos pela Advocacia Pública. Por meio da pesquisa bibliográfica foi utilizado o método hipotético-dedutivo para aferir a compatibilidade dos mecanismos não adversariais no âmbito da Administração Pública frente à indisponibilidade do interesse público.

\section{Palavras-chave:}

Administração Pública. Interesse Público. Advocacia Pública. Consensualidade 


\section{THE PERFORMANCE OF PUBLIC ADVOCACY IN THE CONSENSUAL SOLUTION OF CONFLICTS INVOLVING PUBLIC ADMINISTRATION IN BRAZIL}

\section{Abstract}

The accentuated degree of litigiousness in Brazilian society has produced high congestion rates in the Judiciary. The State is one of the largest litigators in the country. The demands involving the public administration should not necessarily be equated by the State Judge. This paper seeks to discuss the impacts of changes in the Brazilian legal system from 2015 on the use of consensus methods of conflict resolution by State Advocay. Through the bibliographic research, the hypothetical-deductive method was used to assess the compatibility of nonadversarial mechanisms within the scope of Public Administration in the face of the unavailability of the public interest.

Key words

Public administration. Public interest. Public Advocacy. Consensuality.

\section{Introdução}

É reconhecida historicamente a importância da realização da justiça, em seus diferentes sentidos. A partir da Modernidade, a compreensão sobre a realização da justiça foi vinculada ao Estado de Direito, ou seja, as expectativas se voltaram especialmente à prestação jurisdicional, e, portanto, à atuação do Poder Judiciário nos países de jurisdição una.

Observa-se que do Estado absenteísta pós-oitocentista passou-se para um Estado intervencionista a partir do início do Século XX. Desse modo, as relações no ambiente social foram impactadas, cabendo ao Estado de Direito responder a estas novas realidades que conclamam por justiça. Por sua vez, as relações entre o Estado e os cidadãos também se modificaram formal e substancialmente, tornando necessária a revisão e a reestruturação da administração pública.

O tema é dos mais complexos, desafiando sua delimitação a partir da problematização a respeito das políticas públicas do Estado para a realização da justiça. Sensível ao problema, os poderes do Estado republicano têm atuado para estabelecer novos paradigmas para a prestação de justiça no Brasil. O Poder Judiciário, por meio do Conselho Nacional de Justiça, ${ }^{1}$ tem diversificado quanto as práticas de resolução de conflito. Na esfera legislativa, destacam- 
se o Código de Processo Civil de 2015, a Lei 9.307/1996 com as alterações introduzidas pela Lei 13.129/2015, a Lei 13.140/2015 e a Lei de Introdução às normas do Direito brasileiro com as alterações promovidas pela Lei 13.665/2018.

Conquanto estes métodos de resolução de conflitos estejam se integrando ao sistema de justiça no Brasil sem maiores problemas na esfera do direito privado, sua concretização na esfera do direito público apresenta maiores dificuldades, sobretudo relacionadas aos princípios que orientam as atividades da administração pública, dentre os quais se destaca a indisponibilidade do interesse público.

A Lei Complementar Estadual n ${ }^{\circ}$ 144, de 24 de julho de 2018, de Goiás representa um significativo esforço no sentido de alcançar melhores resultados quanto à aplicação dos métodos consensuais para a resolução de conflitos que envolvam a administração pública dessa unidade da Federação. Há, contudo, que se responder ao problema da sua aplicação prática diante da indisponibilidade do interesse público, ou seja, o adequado tratamento da questão dos limites da autonomia da vontade no âmbito da administração pública como fator obstativo das transações envolvendo a Fazenda Pública.

Busca-se neste trabalho debater os efeitos das recentes inovações legislativas sobre a consensualidade na resolução de conflitos entre o cidadão e o Estado, assim como o papel da Advocacia Pública na aplicação dos métodos não adversariais de solução de controvérsias. A pesquisa orientou-se pelo método hipotético-dedutivo, mediante a testagem da hipótese de que o princípio da indisponibilidade pública não constitui obstáculo à realização de transações com a administração pública. O problema de pesquisa foi abordado à luz da teoria da constitucionalização do Direito Administrativo sob uma perspectiva pós-positivista.

\section{A organização da administração pública no Brasil}

As concepções a respeito da administração pública foram desenvolvidas a partir do Iluminismo, uma vez que o absolutismo impedia o reconhecimento e o desenvolvimento dos direitos dos cidadãos e dos deveres do Estado quanto às prestações que este deve realizar em favor daqueles. No Brasil, a organização do Estado brasileiro iniciou-se com a transferência do governo português para o Brasil em 1806. A partir de 1851, foi criada a disciplina de Direito Administrativo nas faculdades de Direito. 
A Constituição Federal de 1988 no capítulo VII, ou seja, a partir do seu artigo 37, trata da administração pública, definindo inicialmente seus princípios fundamentais ${ }^{2}$. Os princípios da legalidade e da eficiência sobressaem-se no estudo a respeito das políticas públicas de tratamento de conflitos.

Observa-se que no Brasil foi adotado o sistema de jurisdição una, ou seja, as demandas que dizem respeito ao Estado são resolvidas pela justiça comum e não por um órgão estatal específico como o Conselho de Estado na França. ${ }^{3}$

A administração pública é a organização estrutural, funcional e finalística do Estado de Direito. Assim, a Constituição Federal estabelece um conjunto de dispositivos que resguardam a ordem pública presente nas atividades estatais, mesmo, nos casos em que atue na esfera do direito privado.

Como ente personalizado, o Estado tanto pode atuar no campo do Direito Público como no do Direito Privado, mantendo sempre sua única personalidade de Direito Público, pois a teoria da dupla personalidade do Estado acha-se definitivamente superada. (MEIRELLES, 2002, p. 59)

A personalidade jurídica do Estado lato senso é definida no artigo 41 do Código Civil brasileiro, ${ }^{4}$ como sendo de direito público interno, compreendendo a União, os Estados, os Municípios, as autarquias e as associações públicas, inclusive outras entidades que sendo criadas por lei, tenham o caráter público. A defesa do Estado no exercício dos atos praticados pela administração pública é realizada pela Advocacia Pública, regida pelos artigos 131 e 132 da Constituição Federal ${ }^{5}$.

De fato, o Estado, a administração pública e a Advocacia Pública são inseparáveis, estando a última vinculada à observância dos princípios da administração pública, na defesa dos interesses primários desta. Considerando que o Estado, sob o ponto de vista da sua

2

$\mathrm{CF} / 88$. Art. 37. A administração pública direta e indireta de qualquer dos Poderes da União, dos Estados, do Distrito Federal e dos Municípios obedecerá aos princípios de legalidade, impessoalidade, moralidade, publicidade e eficiência.

$3 \mathrm{CF} / 88$. Art. $5^{\circ}$, inc. XXXV. a lei não excluirá da apreciação do Poder Judiciário lesão ou ameaça a direito;

4 Código Civil 2002. Art. 41. São pessoas jurídicas de direito público interno: I - a União; II os Estados, o Distrito Federal e os Territórios; III - os Municípios; IV - as autarquias; IV - as autarquias, inclusive as associações públicas; demais entidades de caráter público criadas por lei.

5 Art. 131. A Advocacia-Geral da União é a instituição que, diretamente ou através de órgão vinculado, representa a União, judicial e extrajudicialmente, cabendo-lhe, nos termos da lei complementar que dispuser sobre sua organização e funcionamento, as atividades de consultoria e assessoramento jurídico do Poder Executivo.

Art. 132. Os Procuradores dos Estados e do Distrito Federal, organizados em carreira, na qual o ingresso dependerá de concurso público de provas e títulos, com a participação da Ordem dos Advogados do Brasil em todas as suas fases, exercerão a representação judicial e a consultoria jurídica das respectivas unidades federadas.

Rev. de Formas Consensuais de Solução De Conflitos | e-ISSN: 2525-9679 | Goiânia| v. 5 | n. 1 | p. 21-42 | Jan/Jun. 
finalidade, atua em favor da realização dos interesses da coletividade definidos constitucionalmente, uma conclusão à priori é que este não deveria se envolver em conflitos quanto à realização daqueles fins. Entretanto, sob o ponto de vista funcional, a administração pública defronta-se com uma multiplicidade de situações complexas, tendo como uma de suas consequências o surgimento de conflitos de interesses entre os entes estatais ou entre estes e pessoas de direito privado.

Com o passar do tempo e a ampliação das funções do Estado, na generalidade dos Países, foram surgindo, em grande quantidade, leis específicas e normas constitucionais sobre a Administração Pública.

Elas disciplinam sua organização (Que tipos de órgãos e de entidades a compõem?); seu funcionamento (Como são tomadas e executadas as decisões administrativas?); suas atividades (Quais são os campos em que a administração pode atuar?); e seu patrimônio (Que tipos há de bens públicos, e como podem ser usados pelo Estado ou pelo particular?), suas relações jurídicas (Que poderes tem as autoridades e que direitos tem os particulares?), e seus controles (Que órgãos fiscalizam as autoridades administrativas, e quais seus poderes?) (SUNDFELD, 2014, p. 18)

Esses conflitos se avolumaram em decorrência do reconhecimento de novos direitos e pela adoção de práticas jurídicas que privilegiaram a litigiosidade. Nesse contexto, o Estado assumiu a função jurisdicional para a resolução dos conflitos, sub-rogando-se aos interessados parciais, ou seja, a decisão do Estado-Juiz tem força coercitiva sobre os particulares. Ademais, a segurança jurídica foi considerada uma decorrência do controle estatal da atividade jurisdicional, haja vista as garantias da magistratura ${ }^{6}$.

A partir dos anos de 1990, foram realizadas sucessivas reformas legislativas para tornar o sistema jurídico brasileiro mais eficiente e eficaz, culminando com a Emenda Constitucional $n^{\circ}$ 45/2004. A despeito disso, o Conselho Nacional de Justiça tem diagnosticado uma elevada taxa de congestionamento no Poder Judiciário para o que a Fazenda Pública contribui de modo significativo.

Taxa de Congestionamento: indicador que mede o percentual de casos que permaneceram pendentes de solução ao final do ano-base, em relação ao que tramitou (soma dos pendentes e dos baixados). Cumpre informar que, de todo o acervo, nem todos os processos podem ser baixados no mesmo ano, devido a existência de prazos legais a serem cumpridos, especialmente nos casos em que o deliberação do tribunal a que o juiz estiver vinculado, e, nos demais casos, de sentença judicial transitada em julgado; II - inamovibilidade, salvo por motivo de interesse público, na forma do art. 93, VIII; III irredutibilidade de subsídio, ressalvado o disposto nos arts. 37, X e XI, 39, § 4º 150 , II, 153, III, e 153, § $2^{\circ}$, I 
processo ingressou no final do ano-base. (Conselho Nacional de Justiça - CNJ, Relatório Justiça em números 2018, p. 72)

A maior parte dos processos de execução é composta pelas execuções fiscais, que representam $74 \%$ do estoque em execução. Esses processos são os principais responsáveis pela alta taxa de congestionamento do Poder Judiciário, representando aproximadamente $39 \%$ do total de casos pendentes, e congestionamento de $92 \%$ em 2017 - a maior taxa entre os tipos de processos constantes nesse Relatório. (Conselho Nacional de Justiça - CNJ, Relatório Justiça em números 2018, p. 121)

O século XXI tem sido caracterizado pelo reconhecimento de crises sistêmicas, por discussões em relação aos paradigmas da modernidade e pela generalização da instabilidade social, política, econômica e jurídica. Sob o ponto de vista do acesso à justiça como uma garantia constitucional formal e material, são identificados problemas quanto a morosidade, a efetividade e a segurança.

Admite-se que as consequências da crise sistêmica do Direito relacionam-se com a administração pública, porque sua participação no número de processos no Judiciário é considerável e também em decorrência do modelo de relações institucionais entre os órgãos do Estado e entre estes e o cidadão. Esses aspectos vinculam-se a outros já mencionados, tornando fundamental a revisão a respeito da atuação da administração pública sobre o problema sociológico e jurídico da resolução dos conflitos sob os aspectos da efetividade, a celeridade e segurança.

\begin{abstract}
A segunda medida diz respeito aos novos instrumentos de acesso ao direito e à justiça. Os estudos sociojurídicos voltados para o tema do acesso à justiça têm apontado em diferentes países, a introdução de reformas, processuais ou na estrutura do sistema de justiça, com o fim de universalizar o acesso. [...] Na terceira vaga o movimento de acesso à justiça procura expandir a concepção clássica de resolução jurisdicional de litígios desenvolvendo um conceito amplo de justiça em que os tribunais fazem parte de um conjunto integrado de meios de resolução de conflitos, o que inclui o que se convencionou chamar de ADR (resolução alternativa de litígios). (SANTOS, 2011, p. 49)
\end{abstract}

O Poder Judiciário tem envidado esforços para enfrentar o problema da morosidade, entretanto, no Brasil, a administração pública permanece reticente quanto à sua parcela de responsabilidade nesse fenômeno. A participação da Fazenda Pública na taxa de congestionamento do Judiciário evidencia a necessidade de rediscussão da posição da Advocacia Pública na solução dos conflitos.

\title{
1.1. Fundamentos principiológicos e constitucionais da administração pública
}

A ordem jurídica fundamenta o Estado de Direito que pode ser compreendido como um sistema complexo embasado nas concepções normativistas a respeito do Direito. Desse 
modo, a interpretação e a aplicação do Direito se relacionam com a hermenêutica constitucional. Os estudos a respeito da administração pública, de forma especial, devem se amparar nos seus fundamentos constitucionais.

A observância dos princípios constitucionais quanto à administração pública e ao direito processual podem ser considerados como imperativos para o acesso à justiça, sobretudo, no que se refere ao Estado de Direito, haja vista a sua finalidade quanto a administração do sistema de justiça e a resolução de conflitos. Portanto, retoma-se o artigo 37 da $\mathrm{CF} / 88$ com o enfoque no princípio da legalidade e no princípio da eficiência.

O princípio da legalidade que regula a atividade da administração pública remete ao estudo teórico da norma jurídica e do reconhecimento da força normativa dos princípios de Direito. Atualmente, entende-se que o Direito pode se configurar para além das fronteiras da compreensão da legalidade como um efeito do processo legislativo, em sentido próprio ou a partir das funções derivadas dos poderes do Estado. ${ }^{7}$ Esse reconhecimento é fundamental para se estudar as questões referentes à indisponibilidade do interesse público e as repercussões que apresenta no âmbito da efetivação dos métodos de solução consensual de conflitos pela administração pública, especificamente na conciliação e na mediação. É o que a doutrina tem chamado de princípio da juridicidade:

\begin{abstract}
A vinculação da Administração não se circunscreve, portanto, à lei formal, mas a esse bloco de legalidade (o ordenamento jurídico como um todo sistêmico), a que aludia Hauriou, que encontra melhor enunciação, para os dias de hoje, no que Merkl. chamou de princípio da juridicidade administrativa. Foi essa a influência que determinou a inserção, no art. 20, $\S 3^{\circ}$, da Lei Fundamental de Bonn, da vinculação do Poder Executivo e dos Tribunais à lei e ao direito ( $\sin$ an Gestze und Rech gebunden). Tal ideia, de vinculação ao direito não plasmado na lei, marca a superação do positivismo legalista e abre caminho para um modelo jurídico baseado em princípios e regras, e não apenas nestas últimas. (BINENBOJM, p. 147)
\end{abstract}

Por sua vez, o princípio da eficiência da administração pública refere-se a aspectos funcionais da atividade estatal em sentido amplo, ou seja, a eficiência vincula-se à obtenção dos melhores resultados na atividade administrativa com os menores gastos, tanto econômicos como procedimentais, entendidos como o uso dos recursos pessoais, temporais e outros relacionados com o ato a ser realizado.

Historicamente a teoria da separação dos poderes do Estado, inicialmente proposta por Montesquieu, foi revista, para se reconhecer que as funções exercidas pelos poderes estatais são em alguma medida compartilhadas entre si. Logo, o Poder Legislativo tem a função própria de regular por meio da atividade legislativa, normatizando as relações humanas em suas diferentes dimensões. Contudo, se reconhece que há uma competência residual, em que o legislativo atua como órgão que julga e que executa. Da mesma forma o poder executivo e o poder judiciário atuam com competência residual a fim de cumprir suas funções. 
Desse modo, a eficiência no campo da administração pública, especialmente conflitos em que esta seja parte, deve traduzir a realização da finalidade do Estado que, no caso, relaciona-se com a pacificação do conflito social, como um interesse próprio da coletividade, expresso constitucionalmente. $O$ interesse na solução eficiente implica mútua ponderação entre a efetividade, a razoável duração do processo, a segurança jurídica e a própria indisponibilidade do bem público.

\section{Métodos de resolução de conflitos}

A Constituição promulgada em 1988 adotou um conjunto de direitos que caracteriza o Estado brasileiro como social. ${ }^{8}$ Por outro lado, as medidas adotadas para ampliar o acesso ao Judiciário, como a instituição dos Juizados Especiais, a organização da Defensoria Pública, a estruturação do processo coletivo e a garantia da gratuidade judiciária para as pessoas hipossuficientes, sem que houvesse a estruturação do sistema de justiça, provocou o crescimento da taxa de congestionamento de processos judiciais.

Essa problemática colocou em discussão o fato de que o modelo heterocompositivo de resolução de conflitos realizado na esfera estatal pelos membros da magistratura, ou feito por um árbitro, não deve constituir a única ou a principal forma de solução de conflitos. Os métodos consensuais de resolução de conflitos configuram formas de acesso à Justiça, sendo os mais comuns a negociação direta, a conciliação e a mediação. Além disso, existem as chamadas formas híbridas em que tais métodos são mesclados, mas permanece o objetivo comum de realização de um acordo.

[...] o preceito constitucional que assegura o acesso à Justiça traz implicitamente o princípio da adequação; não se assegura apenas o acesso à justiça, mas se assegura o acesso para obter uma solução adequada aos conflitos, solução tempestiva, que esteja bem adequada ao tipo de conflito que está sendo levado ao Judiciário. (WATANABE, 2003, p.56 apud TARTUCE, 2008, p. 99)

$\mathrm{Na}$ conciliação, um terceiro alheio às partes procura fomentar o acordo, propondo possíveis soluções para o conflito de interesses, o que, normalmente, passa por uma análise outros.

Rev. de Formas Consensuais de Solução De Conflitos | e-ISSN: 2525-9679 | Goiânia| v. 5 | n. 1 | p. 21-42| Jan/Jun. 
das pretensões. Como regra, é utilizada para equacionar disputas decorrentes de relações episódicas entre pessoas desconhecidas (v.g. acidente de trânsito). ${ }^{9}$

Já na mediação, o terceiro facilitador, denominado mediador, procura restabelecer o diálogo entre as partes, sem apresentar propostas de acordo. Ele auxilia as partes a construírem a solução do problema, incentivando-as a desapegar de posições e focar em suas reais necessidades. A mediação é mais utilizada nos casos em que existe uma relação duradoura entre as partes como, por exemplo, litígios na área do direito de família. ${ }^{10}$

A negociação direta, como o próprio nome sugere, não é intermediada por um terceiro. Os próprios interessados, através de conversas e reuniões, buscam um entendimento mútuo quanto a melhor forma de resolver suas disputas, de maneira amigável.

Quando os sujeitos de direito envolvidos no conflito de interesses chegam a uma solução dialogada, observados os requisitos dos negócios jurídicos, ${ }^{11}$ em um ambiente de segurança quanto à manifestação da vontade, ${ }^{12}$ produz-se a Justiça, que neste caso, poderá se configurar de forma ampla, considerando-se a equidade, os princípios gerais de direito, os costumes e outros aspectos culturais, que, entretanto, não firam a ordem pública interna. Sob o ponto de vista da autonomia privada da vontade, a solução dos conflitos pode ser obtida por diferentes tipos negociais, tais como a transação ${ }^{13}$, a renúncia ${ }^{14}$ ou o reconhecimento da procedência do pedido ${ }^{15}$ da parte contrária.

\subsection{A autocomposição na administração pública}

A solução consensual dos conflitos envolvendo a administração pública possui peculiaridades, porque uma das partes do conflito constitui uma realidade jurídica houver vínculo anterior entre as partes, poderá sugerir soluções para o litígio, sendo vedada a utilização de qualquer tipo de constrangimento ou intimidação para que as partes conciliem.

$10 \mathrm{CPC} / 2015$. Art. $165, \S 3^{\circ} \mathrm{O}$ mediador, que atuará preferencialmente nos casos em que houver vínculo anterior entre as partes, auxiliará aos interessados a compreender as questões e os interesses em conflito, de modo que eles possam, pelo restabelecimento da comunicação, identificar, por si próprios, soluções consensuais que gerem benefícios mútuos.

11 Código Civil/2002. Artigo 104.

12 Código Civil/2002. Artigos 138 a 184.

13 Código Civil/2002. Artigos 840 a 850.

14 A renúncia se caracteriza como um ato unilateral de manifestação de vontade em que o titular de um direito material ou processual, atual e existente/incontroverso, abdica , desistindo do exercício desse direito. De acordo com o artigo 108 do CC/2002, o ato de renúncia exige sua lavratura por escritura pública; sendo que o artigo 114 do CC/2002 determina que a renúncia interpreta-se restritamente. Observe-se que de acordo com o artigo 90 do CPC/2015, a sentença fundada em renúncia impõe ao renunciante o ônus das despesas processuais e dos honorários advocatícios.

Código de Processo Civil/2015. Artigo 487, III, 'a'.

Rev. de Formas Consensuais de Solução De Conflitos | e-ISSN: 2525-9679 | Goiânia| v. 5 | n. 1 | p. 21-42 | Jan/Jun. 
instrumental. O regime jurídico de direito administrativo, compreendido como o conjunto de princípios e regras que orientam a atuação da administração pública, impõe aos seus órgãos e entidades uma série de prerrogativas e sujeições (BANDEIRA DE MELLO, 2004; DI PIETRO, 2017).

$\mathrm{Na}$ administração pública, a autonomia da vontade individual é vinculação à norma legal, assimilada na modernidade como a expressão da vontade geral ou da maioria, expressa pelo sistema político representativo dos interesses das coletividades. Assim, aqueles que ocupam os cargos públicos não tem a disponibilidade dos interesses primários da administração pública. No Estado Democrático de Direito, as autoridades públicas são gestoras de interesses alheios, ou seja, cabe a elas zelar pelo interesse público, cuidando para que os bens e direitos integrantes do patrimônio público sejam revertidos em prol da coletividade.

Desse modo, a administração pública sofre restrições quanto à celebração de negócios jurídicos para resolver os conflitos de interesses em que seja parte, ainda que, à priori, a negociação possa resultar em economia e eficiência administrativa, sendo necessário, atender igualmente ao princípio da moralidade administrativa. Portanto, a vontade administrativa se subordina aos princípios constitucionais que orientam a administração pública, bem como às normas jurídicas que autorizam, orientam e circunscrevem os limites para a autocomposição entre os particulares e as pessoas jurídicas de direito público interno.

Nesse contexto, é preciso que os agentes públicos envolvidos na solução de litígios tenham a compreensão sobre as condições para o exercício do dever-poder ${ }^{16}$ para negociar, dando efetividade às normas que orientam a aplicação dos métodos consensuais no âmbito da administração pública. Em 2015, o Congresso Nacional aprovou um conjunto normativo para fomentar a aplicação dos métodos não adversariais de conflitos, criando as condições legais para que a administração pública insira-se de forma mais efetiva nas práticas consensuais de resolução de controvérsias.

Dada a legitimidade político-eleitoral do Poder Legislativo, como o órgão que tem a função primordial de conformar as normas constitucionais e orientar as ações administrativas, buscou-se dar efetividade a autocomposição no âmbito da administração pública. $\mathrm{O}$ art. $3^{\circ}$ do CPC/2015 expressa essa realidade. medida requerida para a realização dos interesses públicos a seu cargo. 
Art. 3 o Não se excluirá da apreciação jurisdicional ameaça ou lesão a direito.

$\S 1$ ó É permitida a arbitragem, na forma da lei.

$\S 2$ o O Estado promoverá, sempre que possível, a solução consensual dos conflitos.

§ 3ำ A conciliação, a mediação e outros métodos de solução consensual de conflitos deverão ser estimulados por juízes, advogados, defensores públicos e membros do

Ministério Público, inclusive no curso do processo judicial.

O sistema jurídico destina-se a reger o comportamento humano e, por isso, pode induzir, promover ou fomentar mudanças sociais por meio da lei. A obrigatoriedade quanto ao uso do cinto de segurança em veículos automotores prevista no Código Brasileiro de Trânsito - Lei 9.503/1997 ${ }^{17}$ é ilustrativa dessa afirmação. Neste mesmo sentido, o complexo normativo integrado pelas Leis $\mathrm{n}^{\mathrm{o}} 13.105 / 2015,13.129 / 2015$ e 13.140/2015 denota o comando do legislador para a adoção de políticas públicas voltadas à aplicação dos métodos complementares de solução de controvérsias.

\section{A indisponibilidade do interesse público}

O princípio da indisponibilidade do interesse público é um dos argumentos em desfavor da aplicação dos métodos consensuais de solução de conflitos na administração pública. Esta questão é norteada por doutrina clássica no sentido de que o Estado tem a titularidade formal do patrimônio público, mas o detém em nome da sociedade. Assim, os gestores públicos não podem dele usar, gozar e dispor livremente. Isso porque os bens públicos estão a serviço da coletividade; são instrumentos de realização de direitos fundamentais.

O Estado não constitui um fim em si mesmo, existindo em função e para garantia do bem-estar dos cidadãos. Conforme esclarece Bandeira de Mello (2004, p. 65) com base nas lições de Ruy Cirne Lima:

[...] a Administração não titulariza interesses públicos. O titular deles é o Estado, que, em certa esfera, os protege e exercita através da função administrativa, mediante o conjunto de órgãos (chamados administração, em sentido subjetivo ou orgânico), veículos da vontade estatal consagrada em lei.

Dessa forma, a celebração de acordos com a Fazenda Pública em decorrência de procedimentos de negociação, mediação ou conciliação, objetivando a solução de conflitos vias do território nacional, salvo em situações regulamentadas pelo CONTRAN.

Art. 167. Deixar o condutor ou passageiro de usar o cinto de segurança, conforme previsto no art. 65:

Infração - grave; Penalidade - multa; Medida administrativa - retenção do veículo até colocação do cinto pelo infrator.

Rev. de Formas Consensuais de Solução De Conflitos | e-ISSN: 2525-9679 | Goiânia| v. 5 | n. 1 | p. 21-42 | Jan/Jun. 
com os administrados depende de previsão legal. É interessante observar que a indisponibilidade dos interesses públicos não implica a impossibilidade da aplicação dos métodos complementares de resolução de conflitos. É o que se depreende do artigo $3^{\circ}$ da Lei 13.140/2015. ${ }^{18}$ Embora a legislação confira poderes à Advocacia Pública para atuar na resolução dos conflitos com particulares em processos administrativos ou judiciais de forma consensual, não fixa parâmetros suficientes sobre os critérios a serem utilizados, revelando lacunas normativas.

Em linhas gerais, a legislação autoriza a autocomposição e a arbitragem, outorgando competência para a Advocacia Pública atuar neste sentido. Por outro lado, o sistema de controle nesses casos é realizado de acordo com o valor econômico objeto do conflito, exigindo o concurso e/ou anuência de autoridades de nível hierárquico superior à medida que cresce a expressão econômica da disputa. Entrementes, há contendas da administração pública sem expressão econômica imediata ou valor financeiro mensurável. Além disso, o Estado se vê envolvido em disputas de diversas naturezas, com diferentes objetos de conflito, tais como o meio ambiente, a proteção ao consumidor, a livre concorrência, o saneamento básico e o próprio serviço público. Justen Filho destaque a multiplicidade de interesses a cargo do Estado e a necessidade de identificar o que merece tutela em cada situação:

\begin{abstract}
A determinação do conteúdo do interesse público produz-se ao longo do processo de produção e aplicação do Direito. Não há interesse público prévio ao Direito, senão como manifestação abstrata insuficiente para determinar uma solução definida. $\mathrm{O}$ processo de concretização do Direito produz a seleção dos interesses, com a identificação do que se reputará como interesse público em face das circunstâncias. Não há qualquer caráter predeterminado (como, por exemplo, a qualidade do titular) apto a qualificar o interesse como público. Essa peculiaridade não pode ser reputada como negativa. Aliás, muito ao contrário, representa a superação de soluções formalistas, inadequadas a propiciar a realização dos valores fundamentais acatados pela comunidade. $\mathrm{O}$ processo de democratização conduz à necessidade de verificar, em cada oportunidade, como se configura o interesse público. (1999, p. 133)
\end{abstract}

Os diversos ramos do direito público possuem especificidades, regras e princípios próprios, impondo limites ao reconhecimento de direitos e obrigações nessas diversas searas, o que impacta na composição dos conflitos com a administração pública. Contudo, a despeito das dificuldades na identificação do interesse público e da multiplicidade de tais interesses consagrados tanto na Constituição quanto na legislação infraconstitucional, entende-se que a 
autocomposição pode ser a melhor forma de realizar a função pública na resolução dos conflitos em que a administração figure como parte.

Os procuradores públicos tem a responsabilidade de exercer a competência para firmar acordos como presentantes do Estado ${ }^{19}$ em conformidade com os objetivos da República, zelando pelo patrimônio público, mas ciente da sua destinação à realização dos direitos fundamentais. Os deveres-poderes conferidos aos advogados públicos para promover a autocomposição, em juízo e fora dele, não constituem um cheque em branco $^{20}$, pois estão limitados não só pela lei em sentido estrito, mas pelos princípios do direito público e do direito administrativo em especial.

\begin{abstract}
No que concerne à advocacia, tem a expressa obrigação ética de estimular, a qualquer tempo, o acordo entre os litigantes, prevenindo a instauração de litigios. Mais: em se tratando de advogados públicos, exige-se, não menos expressamente, que exerçam suas atribuições com 'independência técnica, contribuindo para a solução ou redução de litigiosidade'. (FREITAS, 2017, p. 31)
\end{abstract}

A validade dos acordos firmados pela administração pública por meio da advocacia de Estado depende de adequada fundamentação capaz de demonstrar sua conformidade com o ordenamento jurídico, além do respeito ao princípio da igualdade. Em outras palavras, na aplicação dos métodos não adversariais de solução de controvérsias, é preciso assegurar iguais oportunidades para as partes quanto às condições negociais. Na autocomposição não podem ser estabelecidos favorecimentos e privilégios com relação às partes em conflito ou em relação a determinados sujeitos de direito. Aqueles que estejam em igual situação fática e jurídica devem receber o mesmo tratamento por parte da administração e da advocacia pública. Isso significa que as condições e termos de acordo firmados com uma pessoa devem ser oferecidas às demais em pé de igualdade. Disso resulta, também, a importância de adequada previsão orçamentária de verbas para autocomposição nos acordos que envolvam encargos financeiros para o Estado.

Uma segunda 'limitação' igualmente relevante é o princípio da isonomia. O Poder Público, quando firma um acordo, assim como se dá em qualquer outro ato administrativo, está estabelecendo um precedente - ou seja, todo aquele que se veja em conflito com ente público na mesma situação ou em outra muito similar terá pleno direito de invocar para si a mesma solução, por decorrência evidente do princípio da isonomia. Por tal razão, antes de firmar um determinado acordo, é de representantes, pois estes agem em defesa ou em nome dos incapazes, o que não é o caso do Estado.

20 A liberdade sem a demarcação de limites legais equivaleria ao arbítrio. A discricionariedade é uma possibilidade de escolha balizada pelo Direito. 
necessário que o Poder Público busque averiguar se o conflito em questão é uma situação única ou um conflito repetitivo no qual milhares de pessoas também se enquadram. (SOUZA, 2015, p. 214)

Não havendo controvérsia quanto ao fato e ao direito aplicável em determinada situação concreta, devido a pacificação da matéria na doutrina e na jurisprudência administrativa e/ou judicial, a administração pública tem o dever de reconhecer o direito do cidadão e cumprir espontaneamente as obrigações correlatas. Trata-se de uma exigência do Estado de Direito que significa justamente a submissão do próprio Estado a ordem jurídica.

O Poder Público não deve resistir ou frustrar o cumprimento dos mandamentos legais, assegurando a aplicação do princípio da legalidade. Isto é, o advogado público deve oferecer contestação apenas quanto a pretensões deduzidas perante a administração pública quando verificar que se trate de matéria controvertida ou de fatos não provados. Dessa forma, as universidades públicas, por exemplo, não podem se negar a devolver aos alunos eventuais taxas de matrícula cobradas indevidamente, haja vista a orientação contida na súmula vinculante n. $12 .{ }^{21}$ Observa-se, portanto, que a autocomposição na administração pública não se resume às formas bilaterais, mas também comporta o reconhecimento de pedidos e não ajuizamento ou desistência de ações pela Advocacia Pública.

Por outro lado, entende-se que a Advocacia Pública tem o dever de resistir à pretensões infundadas. $\mathrm{O}$ advogado público não tem poderes para reconhecer a procedência de um pedido qualquer formulado pelo cidadão sem a efetiva demonstração do seu direito subjetivo. Logo, a Fazenda Pública sofre restrições no processo de autocomposição; há impedimento à realização de acordo quanto ao pagamento de uma indenização sem a prova da responsabilidade do agente público no evento danoso. ${ }^{22}$

Ainda quanto às matérias pacificadas, observa-se que a administração pública somente pode fazer ou deixar de fazer algo se previsto em lei. ${ }^{23}$ Ocorre que o Direito exsurge da interpretação/aplicação das normas jurídicas. ${ }^{24}$ Isto é, a normatividade do direito constitui-se sistemicamente ao se considerar os fatos, os princípios gerais de direito, a doutrina, a jurisprudência dos tribunais. Logo, é comum que no julgamento de situações jurídicas

da Constituição Federal.

$22 \quad$ Artigo $37, \S 6^{\circ} \mathrm{CF} / 1988$.

23 Aqui a expressão lei há de ser compreendida em sentido amplo, haja vista a existência de obrigações derivadas imediatamente do próprio texto constitucional, além de normas infralegais expedidas por autoridades não integrantes do Poder Legislativo, como, v.g., o regimento interno dos Tribunais.

24 Na perspectiva da teoria hermenêutica do Direito, entende-se que não é possível separar a interpretação da aplicação do Direito. 
similares e à luz das mesmas normas jurídicas ocorram sentenças diferentes, relativamente ao direito aplicável à espécie.

Um sem-número de questões jurídicas sobre a aplicação do Direito Administrativo suscitam controvérsias quanto à sua interpretação/aplicação ${ }^{25}$, matérias em que não há pacificação jurisprudencial, campo fértil para autocomposição ${ }^{26}$, pois os envolvidos podem construir em colaboração a melhor solução jurídica para o caso concreto, diante dos riscos da sentença. Nessas hipóteses a Advocacia Pública exerce um papel fundamental, pois terá maior liberdade para decidir os termos do acordo.

Nesses casos são retomadas questões de caráter jurídico-filosófico, tais como: os juízes declararam o direito ou criam o direito no momento da sua aplicação ao caso concreto? O que fazer diante das lacunas normativas? Como preencher as lacunas normativas diante de princípios jurídicos colidentes? De que forma é possível controlar a ponderação judicial de princípios e valores constitucionais? A Advocacia Pública pode criar o direito em concurso com o particular em uma negociação direta? Cada uma dessas perguntas desafia extenso trabalho monográfico específico. Em todo o caso, o $\$ 4^{\circ}$ do art. 32 da Lei 13.140/2015 ${ }^{27}$ oferece algum direcionamento para a resposta, ao menos, da última indagação.

\section{O interesse público e o legítimo interesse das partes na autocomposição}

Os conflitos envolvendo a administração pública e os cidadãos demonstram haver disfuncionalidades quanto à realização das funções do Estado de Direito. Em relação às políticas públicas de acesso à justiça consensual, verifica-se a necessidade de treinamento específico para os servidores públicos envolvidos e uma melhor compreensão por parte dos administrados quanto à importância de sua adequada execução tanto para as partes em conflito quanto para o Estado, tendo em vista o cumprimento das finalidades e funções deste. Ocorre que o processo de assimilação de novas práticas é lento e as mudanças trazem consigo equívocos que colocam em risco a viabilidade e a adequação das alterações. Esse é o caso da autocomposição na administração pública.

$25 \quad$ Fenômeno da indeterminação do Direito

26 A indisponibilidade do interesse público não equivale a indisponibilidade do processo judicial. Nas situações de incerteza jurídica, a celebração de acordos é lícita, porque está disciplinado e autorizado pelo Direito, que exige análises sistêmicas sobre os riscos da demanda, além de questões econômicas, políticas, financeiras e orçamentárias. controvérsias que somente possam ser resolvidas por atos ou concessão de direitos sujeitos a autorização do Poder Legislativo. 
O interesse público pode ser definido como a realização dos valores e princípios constitucionais, ou seja, a busca perene do bem-estar da coletividade, por meio da efetivação universal e não discricionária dos direitos humanos. No entanto, a Constituição Federal contempla interesses e valores de diversas ordens, os quais, muitas vezes, entram em choque. Observe-se o art. 170 da Constituição:

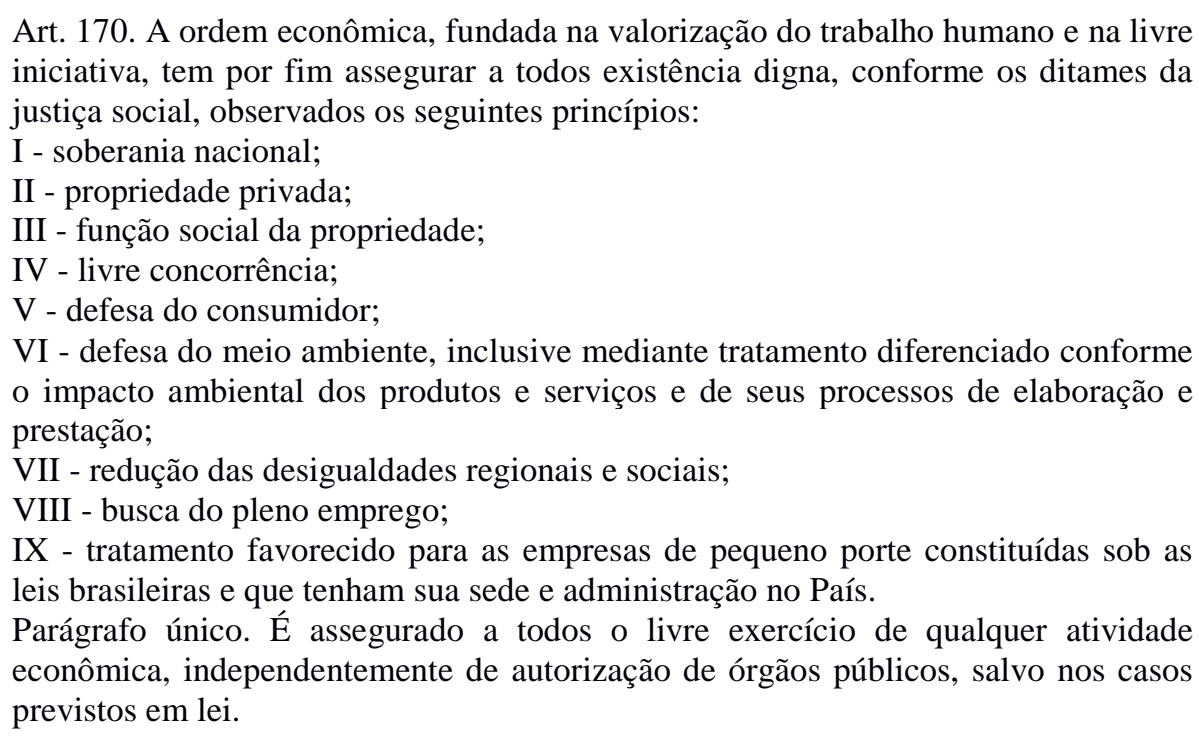

As políticas públicas apresentam-se como os meios que a administração pública adota para viabilizar a concretização dos interesses públicos constitucionalmente definidos. Assim, tais políticas públicas devem contemplar as questões contextuais na sua implementação, a fim de evitar distorções que tornem a atividade do Estado disfuncional. ${ }^{28}$. Enfim, a Constituição muitas vezes protege interesses antagônicos. No campo infraconstitucional, o choque de interesses é ainda mais intenso e evidente. O desafio está em encontrar a justa medida, o equilíbrio.

O desafio, portanto, passa pela compreensão de que, no estágio atual, em que é ressaltado o multilateralismo social, há um conjunto de valores conflituosos, com numerosas aporias e dependências recíprocas, de modo que a escolha discricionária que afeta um determinado aspecto do conjunto social refletirá, nem sempre de forma positiva, em outros segmentos. (GUERRA, 2012, p. 209)

A livre concorrência em tese poderia levar a dominação do mercado por grandes empresas com a consequente extinção das empresas de pequeno porte. A livre iniciativa poderia conduzir a utilização preferencial da terceirização com claro prejuízo à busca do pleno emprego. De igual modo, a plena liberdade de iniciativa tem grande potencial para destruição ou uso não sustentável dos recursos naturais. 
Quanto às funções do Estado de Direito, verifica-se uma multiplicidade de ações para a concretização do interesse público por intermédio da administração pública. Não se pode olvidar, ainda, a necessidade do Poder Público assegurar o princípio da isonomia, tratando de forma desigual os cidadãos na justa medida da sua desigualdade. ${ }^{29} \mathrm{~A}$ adoção de critérios de diferenciação no tratamento dos cidadãos por parte da administração pública há de ser motivada e justificada a partir de discrímens válidos e racionais, ou seja, amparados pelo sistema normativo, com vista a dar efetividade às normas constitucionais. Conforme leciona Gustavo Binenbojm (2004, p. 91), "uma democracia somente pode ser considerada um governo segundo a vontade do povo se os cidadãos são tratados como agentes morais autônomos, tratados com igual respeito e consideração."

Também é preciso ter presente que os direitos têm custos e que os recursos públicos são escassos. Daí a importância da institucionalização de políticas públicas de forma justa, transparente e democrática, a fim de que todos interessados possam participar da sua concepção, execução e controle, promovendo justiça social.

Por outro lado, diante da inevitabilidade dos conflitos sociais é necessário definir políticas públicas que possibilitem o adequado e complementar tratamento destes com a consequente solução consensual de demandas, especialmente as de natureza coletiva, reduzindo a sobrecarga do Poder Judiciário e, ao mesmo tempo, aumentando o grau de satisfação das pessoas com a administração por meio de um diálogo profícuo com os presentantes do Estado.

O emprego institucional, republicano e criterioso dos métodos não adversariais de solução de conflitos envolvendo a administração pública constitui uma exigência do Estado Democrático de Direito, na medida em que propicia a satisfação de direitos de maneira mais célere, dialogada, eficiente, eficaz e efetiva. A celeridade e a eficiência podem ser alcançadas com a simplificação e flexibilidade dos procedimentos. A eficácia é fruto do reconhecimento e validade emprestada aos acordos pelo ordenamento jurídico. Por fim, a efetividade resulta da maior aceitação e compromisso das partes com a solução por eles concebida em conjunto. Em síntese, a autocomposição interessa tanto ao Estado quanto aos particulares, pois a todos beneficia a justa solução do conflito em tempo razoável e com o menor dispêndio de recursos possível. vulnerabilidade social devem receber assistência social por parte do Estado, os grupos marginalizados precisam de ações afirmativas e assim por diante. 


\section{O sistema autocompositivo na Procuradoria-Geral do Estado de Goiás}

Antes mesmo do advento dos Juizados Especiais da Fazenda Pública, a lei orgânica da Procuradoria-Geral do Estado de Goiás - Lei Complementar n ${ }^{\circ}$ 58/2006 autorizava o Estado a transigir $^{30}$ em ações judiciais, por intermédio do Procurador-Geral (art. 5 $5^{\circ}, \mathrm{VI}$ ), mediante autorização do Governador. Com a aprovação da Lei Complementar no 99, de 27 de abril de 2012, os Procuradores do Estado foram autorizados a "conciliar, transigir, confessar, deixar de recorrer, desistir de recursos interpostos, concordar com a desistência e com a procedência do pedido", nas demandas de até 60 (sessenta) salários-mínimos.

Na aplicação da sistemática de resolução de conflitos por meio da legislação citada anteriormente, foram estabelecidas as seguintes cláusulas mínimas do termo de acordo: i) renúncia da parte contrária a eventuais direitos decorrentes do mesmo fato ou fundamento jurídico que deu origem à demanda judicial; ii) previsão dos honorários advocatícios e a responsabilidade por seu pagamento.

Ademais, a lei estabeleceu alguns requisitos para a transação, a não interposição e a desistência do recurso já apresentado: i) existência de erro administrativo reconhecido pela autoridade competente ou verificável pela análise das provas e documentos que instruem o processo pelo próprio Procurador do Estado, mediante motivação adequada; ii) a inexistência de controvérsia quanto ao fato e ao direito aplicado, reconhecidos por súmula ou jurisprudência dominante dos tribunais; iii) tratar-se de orientação consolidada no âmbito da Procuradoria ou quando houver súmula administrativa contrária à pretensão. Além disso, o diploma legal em comento assentou a impossibilidade de acordo nos litígios fundados exclusivamente em matéria de direito quando houver orientação ou súmula administrativa contrária à pretensão.

A Lei Complementar $\mathrm{n}^{\circ}$ 144, de 24 de abril de 2018, por sua vez, ampliou a possibilidade de o Procurador do Estado "conciliar, transigir, abster-se de contestar, realizar autocomposição, firmar compromisso arbitral, confessar, deixar de recorrer, desistir de recursos interpostos, concordar com a desistência e com a procedência do pedido" nas causas de até 500 (quinhentos) salários-mínimos. Essa mesma norma legal instituiu, na Procuradoria, a Câmara de Conciliação, Mediação e Arbitragem Estadual (CCMA) com o objetivo, entre outros, de promover e estimular a adoção de medidas para autocomposição de litígios judiciais e controvérsias administrativas. 
É interessante observar que a legislação estadual mencionada guarda conformidade com a chamada lei nacional de mediação - Lei 13.140, de 26 de junho de 2015, cujo artigo 32 estabelece que, compete aos órgãos da Advocacia Pública, nas respectivas esferas de atuação, examinar a admissibilidade dos pedidos de autocomposição entre a pessoa jurídica de direito público e os particulares.

Apesar dos esforços legislativos, registra-se que a experiência da Procuradoria-Geral do Estado na autocomposição, antes da LC 144/2018, restringiu-se a algumas situações pontuais. ${ }^{31}$ Os Procuradores do Estado tem uma formação jurídica baseada na atividade adversarial quanto ao exercício profissional ${ }^{32}$. Entre outros fatores que influenciam esta concepção de atuação jurídica, sabe-se que a formação acadêmico-jurídica até recentemente se limitava ao estudo do direito processual segundo o modelo heterocompositivo estatal de resolução de conflitos. Os métodos autocompositivos e o arbitral eram tratados como uma exceção baseada no interesse das partes, sem ter em consideração, o interesse público na eficiência na prestação jurisdicional.

A falta de uma cultura da consensualidade pode explicar a dificuldade dos advogados públicos na busca por soluções conciliatórias. Por outro lado, diante do princípio da indisponibilidade do interesse público parece ter havido uma opção pela cautela quanto a aplicação dos métodos consensuais de solução de conflitos, privilegiando a decisão do conflito pelo Estado-Juiz. ${ }^{33}$ Esta situação, contudo, colide com a função do Estado em efetivar os direitos fundamentais especialmente os do acesso material à Justiça e da razoável duração dos processos (art. $5^{\circ}$, LIV e LXXVIII).

As dificuldades da Advocacia Pública em ampliar o uso dos métodos não adversariais de solução de conflitos é descrita com propriedade por Varella e Ferreira Filho (2019, p. 161): remuneratórias. Transações por adesão com servidores civis para pagamento das diferenças salariais previstas no art. $4^{\circ}$ da Lei estadual n. 16.036/2007. Transações por adesão para pagamento de diferenças de $13^{\circ}$ salário relativo a reajustes concedidos após o aniversário.

32 Os cursos de graduação em Direito ofereciam uma formação voltada para o litígio com preponderância de técnicas e conhecimentos em matéria processual dirigidas a obtenção de decisão favorável perante o juiz. Não havia na matriz curricular obrigatória dos cursos de Direito, disciplinas voltadas à negociação, mediação, conciliação. Observe-se que há uma tendência à superação desse problema, pois a Resolução CNE/CES n ${ }^{\circ} 5$ de 17/12/2018 busca alterar esta realidade ao prever no artigo $5^{\circ}$, II que na perspectiva formativa do graduando em direito, sua formação técnico-jurídica deve abranger os estudos as formas consensuais de solução de conflitos.

33 Os procuradores públicos, aparentemente, receavam e ainda receiam ser questionados por eventuais acordos firmados como 'presentantes' da Fazenda Pública pelos órgãos de controle, especialmente Ministério Público e Tribunais de Contas. 
Os órgãos da advocacia pública realizam acordos, mas são limitados por uma diversidade de fatores, como as limitações legais, os receios de órgãos de controle, a ausência de incentivos internos e externos e assim por diante. Não há, efetivamente, uma política pública consensual que estimule a atuação consensual do agente público, o que enseja a manutenção da crise vivenciada na gestão de litígios pelo Poder Judiciário.

Em todo o caso, com o advento da citada LC no 144/2018, o Estado de Goiás demonstra seu compromisso com o desenvolvimento de uma cultura da paz e de priorização da consensualidade no âmbito da administração pública com a efetiva instalação da Câmara de Conciliação, Mediação e Arbitragem - CCMA. O primeiro acordo intermediado pela Câmara foi formalizado em 29 de novembro de $2018 .{ }^{34}$ De lá para cá já se tem notícia de vários outros processos resolvidos pela via amigável. Desse modo, os Procuradores do Estado demonstram seu compromisso com as práticas consensuais de solução de conflitos.

À medida que os acordos celebrados mostrarem os resultados positivos, como a aproximação entre o cidadão e administração pública, o aumento da arrecadação, a diminuição de gastos com processos e condenações judiciais, a maior disponibilidade de tempo para ações preventivas e domínio das técnicas de conciliação e mediação, será possível uma análise qualitativa e quantitativa das políticas públicas de acesso à justiça junto à Procuradoria-Geral do Estado em Goiás, tanto em relação à taxa de congestionamento no Tribunal de Justiça quanto à litigância envolvendo a administração pública, além da satisfação do jurisdicionado com a prestação de justiça em Goiás.

\section{Conclusão}

Um país de modernidade tardia como o Brasil, ainda não foi capaz de colocar em prática as promessas constitucionais. A ineficiência quanto à gestão dos recursos públicos, os problemas na execução das políticas públicas educacionais e o deficit na concretização dos direitos sociais têm consequências graves para o sistema de justiça.

Admitiu-se que a litigiosidade envolvendo o Estado impacta na taxa de congestionamento do Poder Judiciário, sendo que uma das formas encontradas pelo legislador

Em 2003, o Estado ajuizou ação de indenização em face de uma cidadã por ter provocado dano a uma viatura da Polícia Civil em acidente de trânsito no valor de $\mathrm{R} \$ 4.750,00$. A sentença condenatória foi proferida em 10/05/2004. A ré interpôs recurso de apelação. O acórdão foi proferido em 25/08/2005. Após o trânsito em julgado, houve execução. Em consulta aos Cartórios de Registro de Imóveis e ao Departamento de Trânsito não foram localizados bens em nome da devedora. Após quinze anos de tramitação do processo judicial com todos custos envolvidos o dano ao erário não tinha sido reparado. $\mathrm{O}$ acordo possibilitará o recebimento ao menos em parte do crédito. Foi pactuado o pagamento da quantia de $\mathrm{R} \$ 5.000,00$ (cinco mil reais) em duas parcelas. (Processo n. 201800003014143). 
para resolver este problema foi o fomentar a utilização dos métodos complementares de solução de conflitos, regulamentando a possibilidade de sua utilização para as demandas da administração pública. Contudo, as normas legais a respeito da consensualidade na resolução dos conflitos da administração pública não tem se mostrado suficientes para superar as barreiras ao emprego da autocomposição na escala desejável.

As lacunas existentes na legislação e a resistência cultural aos métodos complementares de resolução de controvérsias aumentam a responsabilidade da Advocacia Pública na promoção da solução pacífica dos conflitos da administração pública, pois deve encontrar respostas constitucionalmente adequadas aos casos concretos sem adentrar ao campo reservado ao legislador, respeitando a isonomia entre os cidadãos.

Em Goiás, a Procuradoria-Geral do Estado, à vista da Lei Complementar 144/2018, deve assumir um papel de protagonismo na aplicação dos métodos complementares de solução de conflitos com a instalação da Câmara de Conciliação, Mediação e Arbitragem da Administração Estadual, sem descurar da força normativa dos princípios previstos no art. 37 da Constituição Federal.

A busca permanente pelo aperfeiçoamento e pela expansão de políticas públicas de solução adequada de conflitos impõe às autoridades públicas e aos órgãos integrantes do sistema de justiça o dever de resolver os conflitos de forma adequada com o menor dispêndio possível de recursos materiais e humanos em tempo razoável.

A utilização da conciliação, da mediação e da negociação direta para a resolução dos conflitos com a administração pública deverá se constituir como a melhor forma de realizar o interesse público, haja vista que a concretização dos direitos fundamentais, como o acesso à justiça, é uma das finalidades primordiais do Estado.

A indisponibilidade do interesse público não constitui óbice à autocomposição no âmbito da administração pública, pois a lei autoriza, nas condições que estabelece, a realização de acordos entre particulares e os órgãos estatais com o objetivo de extinguir conflitos de forma consensual.

Caberá a Advocacia Pública criar padrões e critérios seguros para a condução de transações entre a administração pública e os cidadãos, sem prejuízo da fundamentação circunstanciada dos acordos, mediante a exposição e publicação das razões de fato e de direito capazes de demonstrar as vantagens da solução amigável em cada caso concreto. 


\section{REFERÊNCIAS}

BANDEIRA DE MELLO, Celso Antônio. Curso de Direito Administrativo. 17. ed. São Paulo: Malheiros Editores, 2004.

BINENBOJM, Gustavo. A nova jurisdição constitucional brasileira: legitimidade democrática e instrumentos de realização. 2 ed. Rio de Janeiro: Renovar, 2004. Uma teoria do Direito Administrativo: Direitos Fundamentais, Democracia e Constitucionalização. 3 ed. Rio de Janeiro: Renovar, 2014.

DI PETRO, Maria Sylvia Zanella. Direito administrativo. 30. ed. Rio de Janeiro: Forense, 2017.

FREITAS, Juarez. Direito administrativo não adversarial: a prioritária solução consensual de conflitos. RDA - Revista de Direito Administrativo, Rio de Janeiro, v. 276, p. 25-46, set./dez. 2017.

GUERRA, Sérgio. Discricionariedade administrativa: limitações da vinculação legalitária e propostas pós-positivistas. In: ARAGÃO, Alexandre Santos de; MARQUES NETO, Floriano de Azevedo (Coord.). Direito administrativo e seus novos paradigmas. Belo Horizonte: Fórum, 2012, p. 205-237.

JUSTEN FILHO, Marçal. Conceito de Interesse Público e a "Personalização" do Direito Administrativo. In Revista Trimestral de Direito Público, n. 26, São Paulo: Malheiros, 1999.

MEIRELLES, Hely Lopes. Direito Administrativo brasileiro. 27 ed. São Paulo: Malheiros editores, 2002.

SANTOS, Boaventura de Sousa. Para uma revolução democrática da justiça. Coimbra: Edições Almedina, 2011.

SOUZA, Luciane Moessa de. Mediação de conflitos e administração pública. In: HALE, Durval; PINHO, Humberto; CABRAL, Trícia Navarro Xavier (org.). O marco legal da mediação no Brasil: comentários à lei no 13.140, de 26 de junho de 2015. São Paulo: Altas, 2016. p. 207-228.

SUNDFELD, Carlos Ari. Direito administrativo para céticos. 2 ed. São Paulo: Malheiros Editores, 2014.

TARTUCE, Fernanda. Mediação nos conflitos civis. 2. ed. São Paulo: Método, 2015.

VARELLA, Marcelo; FERREIRA FILHO, Marcílio. Políticas públicas consensuais e o estimulo à negociação pelo agente público. $A \& C-$ Revista de Direito Administrativo \& Constitucional, Belo Horizonte, ano 18, n. 74, p. 147-173, out./dez.2018. 